\title{
@OPENACCESS MATERNAL KNOWLEDGE OF INFANTILE DIARRHEA: \\ Check for updates A CROSS SECTIONAL STUDY IN PRIVATE TEACHING HOSPITALS OF DISTRICT PESHAWAR-PAKISTAN
}

\begin{abstract}
${ }^{1}$ Student, Peshawar Medical College, Riphah International University, Islamabad-Pakistan

${ }^{2}$ Department of Community Medicine, Peshawar Medical College, Riphah International University, Islamabad-Pakistan
\end{abstract}

Address for correspondence: Farhat Rehana Malik Department of Community Medicine, Peshawar Medical College, Riphah International University, Islamabad-Pakistan.

E-mail:

drfarhatmalik@gmail.com

Date Received:

December, $7^{\text {th }} 2020$

Date Revised:

September, 13 $3^{\text {th }} 2021$

Date Accepted:

October, $6^{\text {th }} 2021$

\author{
Mohammad Haris ${ }^{1}$, Farhat Rehana Malik² ${ }^{\boxplus}$, Sohail Ahmad ${ }^{1}$, Syed Maaz Ali Shah ${ }^{1}$, Saqib Sultan ${ }^{1}$, \\ Zia Ullah Shah ${ }^{1}$
}

\section{ABSTRACT}

Objective: To evaluate maternal knowledge regarding causes, signs and management of infantile diarrhea.

Methodology: This descriptive study was conducted at Pediatrics wards of two Private Teaching Hospitals of District Peshawar from 10th January 2020 to 10th March 2020. A total of 150 mothers were recruited whose children were admitted in Pediatric wards through convenient sampling technique with informed consent. A validated questionnaire was used for eligible mothers' personal interviews in their local languages i.e Urdu and Pushto. The collected data was stored and analyzed in SPSS v.21.0; descriptive and inferential statistics were used as needed.

Results: The maternal mean age was $28 \pm 7.74$ years with overall response rate of the questionnaires as $98 \%$. Knowledge of diarrhea as watery stool was appreciated by $97(64.66 \%)$ mothers, however, 10(6.66\%) mothers had no idea about this. Evil eye was considered by $72(48 \%)$ mothers as the cause behind diarrhea, followed by contaminated water $39(26 \%)$, and teething $10(6.66 \%)$. Maternal knowledge of danger signs came out to be as weakness/lethargy $74(49.33 \%)$, followed by marked thirst for water 46(30.66\%), and repeated vomiting 24(16\%). The use of ORS for 24 hours was recognized by 30(20\%) mothers, timings of ORS after every stool by 36(24\%) mothers, and 94(62.66\%) mothers were unaware about ORS usage. A significant association between maternal education and maternal knowledge was established with $p$ value of $<0.05$.

Conclusion: Maternal knowledge of causes, signs and management of infantile diarrhea was better in educated mothers.

Keywords: Knowledge; Mothers; Childhood diarrhea; Practice; Management.

\section{INTRODUCTION}

Diarrhea is defined as the passage of three or more loose or liquid stools per day, considered abnormal by the mother and stools more frequent than normal for a child. ${ }^{1,2}$ Diarrhea is caused by bacterial, viral and parasitic organisms, spread through contaminated food, drinking-water and from person-to-person as a result of poor hygiene. ${ }^{1}$ Diarrhea is one of the leading causes of death among children under five globally. This is the commonest disease with a negative impact upon children growth and development. More than one in ten child deaths - about 800000 each year is due to diarrhea. Global estimates show an average of $3.2 \mathrm{di}$ arrheal episodes among under five children, with 1.87 million falling prey to dehydration related deaths in Asia, Africa and Latin America. ${ }^{2}$ Diarrhea is the second leading cause of child morbidity, mortality and undernutrition especially in the developing countries. It kills young children more than HIV/AIDS, malaria and mea- sles combined. ${ }^{2-4}$

Diarrheal diseases are a major public health problem among infants as well as children specially in low income countries, by faeco-oral route through contaminated food/ water. Severe fluid depletion and dehydration occurs without proper treatment. Major cause behind diarrhea includes lack of hygiene, unsafe human waste disposal, poor hand washing practices and contaminated water and food intake. This study also shows low level of maternal knowledge, attitudes and practices towards diarrheal management and prevention in rural and urban settings. ${ }^{5}$ Diarrheal diseases contributes towards $15 \%$ of all under-five deaths, making it the second leading cause of death. Diarrheal illnesses impair weight as well as height gains, with the greatest effects being seen with recurrent illnesses. Lack of maternal education, lack of availability of latrine, rural residence and lack of maternal hand washing are significantly associated with childhood diarrhea. ${ }^{6}$ A cross sectional 
study of Ethiopia showed good knowledge of mothers however, negative attitude towards home based management of diarrhea and prevention. ${ }^{2}$ IMNCI guidelines advice use of ORS, ORT with zinc and breast feeding for diarrheal appropriate management. However, maternal knowledge and attitudes are largely dependent upon their use. In the last 25 years ORS prevented 50 million deaths globally, but poor knowledge of the mothers in this regard posed a great threat. ${ }^{7}$ Mother's knowledge and education is very important in the management of diarrhea. A study in Lahore region of Pakistan gave good knowledge of mothers and significant association of their knowledge with practices. ${ }^{8}$

Although global researches are too many on this subject but this particular topic has not yet been explored in Peshawar- KPK Pakistan i.e maternal knowledge about diarrhea, causes, management and prevention. To fill this gap, this study was conducted as a hospital based study in Pediatrics ward of Private Teaching Hospitals of Peshawar with pre-approved validated questionnaires for maternal interviews in order to assess their knowledge regarding diarrhea to identify it earlier to save lives of children and determine the association of maternal knowledge with their education.

\section{METHODOLOGY}

This descriptive study was conducted at Pediatrics wards of two Private Teaching Hospitals of District Peshawar from $10^{\text {th }}$ January 2020 to $10^{\text {th }}$ March 2020. The sample size of 151 mothers, was calculated through RAOSOFT online sample size calculator with 95\% confidence interval, $7.97 \%$ margin of Error, population size assumed as 20,000 and response distribution rate at $50 \% .{ }^{9}$ Non-randomized convenient sampling technique was used in the study.

The study was conducted after taking approval from the institutional Ethical Research Committee (ERC Approval Number: Prime/ ERC/2019-12). The purpose and benefits of the study were thoroughly explained to all the recruited mothers and a written informed consent was obtained. All the mothers whose children were admitted in the respective wards of the included hospitals were included in the study with at least one child of less than 2 years of age with complaint of diarrhea in the past two months. The mothers who failed to give consent and could not communicate due to lingual barrier were excluded from this study. A validated questionnaire ${ }^{4}$ (annexure 1) was used to conduct personal interviews from the included mothers.
This research tool had 20 odd questions with multiple possible options in English language but interviews were held in Urdu and Pashto according to the language of participant. Researchers were trained beforehand and then they asked questions in Urdu/Pashto with filling the questionnaire.

The data was stored and entered in SPSS. Coding was done prior to entry into SPSS Version-21. Descriptive statistics of socio-demographic variables, knowledge, causes, danger signs and management were presented as frequency and percentages with mean and standard deviations as well.

\section{RESULTS}

The response rate of the mothers interviewed was $98 \%$, with maternal mean age as $28 \pm 7.74$ years. Maternal socio-demographic statistics showed respondents age groups as $<20$ Years $(n=23 ; 15.33 \%), 21-30$ Years $(n=68 ; 45.33 \%), 31-40$ Years $(n=41$; $27.33 \%)$ and $>40$ years showed $(n=18$; 12.00\%). Maternal occupation showed $29(19.33 \%)$ as working mothers whereas $121(80.66 \%)$ as house wives. Educational status showed $23(15.33 \%)$ mothers unable to read/write, $26(17.33 \%)$ as primary level educated, 50(33.33\%) completed secondary

Table 1: Maternal Knowledge about Diarrhea.

\begin{tabular}{|c|c|c|c|}
\hline \multicolumn{2}{|c|}{ Diarrhea } & Frequency & Percentage \\
\hline \multirow{4}{*}{ Definition } & Watery stool & 97 & 64.66 \\
\cline { 2 - 4 } & Non-watery stool & 23 & 15.33 \\
\cline { 2 - 4 } & Blood in stool & 17 & 11.33 \\
\cline { 2 - 4 } & Greenish stool & 3 & 2.00 \\
\cline { 2 - 4 } & No idea & 10 & 6.66 \\
\hline \multirow{4}{*}{ Causes } & Teething & 10 & 6.66 \\
\cline { 2 - 4 } & Evil eye & 72 & 48.00 \\
\cline { 2 - 4 } & Contaminated water & 39 & 26.00 \\
\cline { 2 - 4 } & No idea & 29 & 19.33 \\
\hline \multirow{3}{*}{ Danger signs } & Weak or Lethargic & 74 & 49.33 \\
\cline { 2 - 4 } & Repeated Vomiting & 24 & 16.00 \\
\cline { 2 - 4 } & Fever and Blood in Stool & 06 & 4.00 \\
\hline
\end{tabular}




\begin{tabular}{|c|c|c|c|}
\hline \multirow{3}{*}{ ORS Timings } & After every stool & 36 & 24.00 \\
\hline & Once a day & 28 & 18.66 \\
\hline & 2-3 times a day & 44 & 29.33 \\
\hline \multirow[b]{2}{*}{ Uses of ORT } & Adds lost water & 33 & 22.00 \\
\hline & Cure diarrheal disease & 23 & 15.33 \\
\hline \multirow{3}{*}{ ORS Life } & 48 Hours & 46 & 30.66 \\
\hline & 72 Hours & 24 & 16.00 \\
\hline & 96 Hours & 50 & 33.33 \\
\hline ORT at home & Yes & 118 & 78.66 \\
\hline \multirow{5}{*}{ Seek help First } & Hakeem & 22 & 14.66 \\
\hline & Faith Healers & 48 & 32.00 \\
\hline & Private Drug Shop & 40 & 26.66 \\
\hline & Health Center & 16 & 10.66 \\
\hline & Hospital & 24 & 16.00 \\
\hline \multirow{4}{*}{ Breastfed Duration } & Less & 57 & 38.00 \\
\hline & Same & 37 & 24.66 \\
\hline & More & 42 & 28.00 \\
\hline & No Breastfeeding & 14 & 9.33 \\
\hline
\end{tabular}

level and tertiary level educated came out to be $51(34.00 \%)$. The number of children born to the females were one $37(24.66 \%)$, two $34(22.66 \%)$, three $61(40.66 \%)$ and more than three $18(12.00 \%)$

Maternal knowledge regarding definition and cause of diarrhea is given in detail in Table No. 1. Very low percentage of mothers knew the right cause of diarrhea i.e. contaminated food or water, however, comparatively higher percentage of mothers knew the exact proper definition of diarrhea. Table No. 1 also shows detailed statistics of maternal knowledge regarding danger signs of diarrhea. Over half of the mothers were unaware about danger signs associated with diarrhea. Maternal management of childhood diarrhea in relation to ORS timings, ORT uses, ORS life, the preparation, breast feeding duration during diarrhea and hand hygiene is detailed in Table №.1

\section{DISCUSSION}

Good maternal knowledge (65.2\%) with unsatisfactory attitudes (54\%) and practices (58\%) against under five children diarrhea management were shown in a cross sectional study. These results are consistent as far as knowledge is concerned however, present study had good scores in educated mothers only and the present study did not take into account maternal attitudes and practice. ${ }^{2}$ Another study showed low level of maternal knowledge, attitudes and practices in prevention and management of diarrhea while educated mothers in urban settings with tertiary level education showed significant $p$ value (0.04). ${ }^{5}$ These results are consistent with the present study, however attitudes and practices were missing from it. A Nepalese study showed maternal literacy as $93.2 \%$, with good knowledge of mothers in management of diarrhea through ORS (92.5\%). Associations of maternal knowledge with variables like age, religion, level of education and previous history of diarrhea showed significant $p$ values. The study results showed high impact of mother's education in the management and prevention of diarrhea with increased trend of ORS use in diarrhea which is encouraging. ${ }^{7}$ This study goes in correlation with the present study 
findings and comparable with maternal education and knowledge that showed significant associations.

A study conducted in Khyber Medical University Peshawar depicted maternal knowledge as 58\% about diarrhea, with $80.4 \%$ mothers having correct knowledge and practice of ORS preparation. Positive attitude of the mothers was revealed regarding use of ORS in prevention of diarrhea. ${ }^{10}$ Findings of this study were consistent with the present study but with missing maternal attitude only. An Indian study revealed poor knowledge of diarrhea (47\%) with good information regarding causes (52\%) and risk factors of diarrhea (58\%). Danger signs were known by only $34 \%$ mothers, ORS preparation knowledge (19\%) and restriction of food during diarrhea by $83 \%$ of mothers. ${ }^{11}$ However, these results are not comparable with the present study which had good knowledge of the mothers regarding diarrhea and ORS preparation at home.

A study in Egypt showed 25\% of mothers understood the right use of ORT which significantly increased after interventions. A large proportion (38\%) of the mothers either stopped breastfeeding or did not increase its frequency (34\%) during the illness i.e., diarrhea. ${ }^{12}$ These results are comparable with the present study. Maternal education and maternal socioeconomic status has important role in determining knowledge, attitude and practice of her children in diarrheal disease, which came out to be significant in this study with maximum mothers from middle and lower class. Maternal education was also significant with knowledge, although but with poor knowledge depicted among illiterate mothers. ${ }^{13}$ Similar results were shown in the present study. A cross sectional study showed one fifth respondents as literate, poor mean knowledge scores for hygiene and diarrheal prevention however, significant scores of educated mothers with maternal knowledge ( $p$ value $<0.05$ ) of hand hygiene and diarrheal prevention. Only $50.4 \%$ and $55.2 \%$ mothers knew the correct method of ORS preparation and administration. ${ }^{14}$ Similar results were depicted in the present study as well.

Among the limitations, one was that study a hospital-based study, where mothers might have been given health education regarding diarrhea so their level of knowledge would be different from mothers in the community. Furthermore, since it was conducted in urban area, the level of knowledge of rural mothers would probably not be the same as recorded in this study. Lastly, as data was collected in months of January and February when there is relatively low prevalence of diarrhea as compared to months like July and August, the results in other months might be different.

\section{- CONCLUSION}

Maternal knowledge of causes, signs and management of infantile diarrhea was better in educated mothers.

\section{REFERENCES}

1. World Health Organization. Diarrhea. https://www.who.int/topics/diarrhoea/ en/ (2020, accessed 20 March 2020).

2. Workie HM, Sharifabdilahi AS, Addis EM. Mothers' knowledge, attitude and practice towards the prevention and home-based management of diarrheal disease among under-five children in Diredawa, Eastern Ethiopia, 2016: a cross-sectional study. BMC Pediatr. 2018; 18(1): 358. DOl: https://doi. org/10.1186/s12887-018-1321-6.

3. World Health Organization. Maternal Child Adolescent. www.who.int/ maternal_child_adolescent/documents/9789241598415/en/ (accessed 20 March,2020).

4. Mumtaz Y, Zafar M, Mumtaz Z. Knowledge attitude and practices of moth- ers about diarrhea in children under 5 years. J Dow Univ Health Sci. 2014; 8(1): 3-6.

5. Adeleke Al, Mhlaba T. Maternal Knowledge, Attitudes and Practices towards Prevention and Management of Child Diarrhoea in Urban and Rural Maseru, Lesotho. Int J Trop Dis Health. 2019; 36(2): 1-20.

6. Crawford SE, Ramani S, Tate JE, Parashar UD, Svensson L, et al. Rotavirus infection. Nat Rev Dis Primers. 2017; 3(1):1-6.

7. Shah S, Shreshta M, Sharma B, Pandey N, Dahal S. Knowledge and Practice on Childhood Diarrhea among Mothers having Children Under Five Years of Age in Madhuban, Sunsari- Nepal. Religion. 2019; 20(42):29-1.

8. Shahzad S, Faroog SA, Noor A, Batool SF, Alvi Q, Amir T, et al. Association of Maternal Knowledge and Practices Regarding Prevention and Care of Diarrhea at Home for Children less than 5 years of Age: A Study Conducted in Tertiary Level Hospitals of Lahore, Pakistan. Int Arch BioMed Clinical Res. 2018;4(2): 68-72.

9. Raosoft. Sample Size Calculator Online http://www.raosoft.com/samplesize. html. (accessed 11September, 2021).

10. Hanif Z, Afridi A, Kibria Z, Maroof A, Sumayyah E. Knowledge, Attitude and Practice of Mothers regarding the use of Oral Rehydration Solution in children's suffering from diarrhea. J Khyber Coll Dent. 2018;8(1): 37-40.

11. Padhy S, Sethi RK, Behera N. Mother's knowledge, attitude and practice regarding prevention and management of diarrhea in children in Southern Odisha. Int J Contemp Pediatr. 2017;4(3): 96671.

12. Abdel-Aziz S. B, Mowafy MA, Galal YS. Assessing the Impact of a Community-Based Health and Nutrition Education on the Management of Diarrhea in an Urban District, Cairo, Egypt. Glob J 
Health Sci. 2016; 8(2): 46-55.

13. Mutalik AV, Raje WV. Relationship between maternal education and socioeconomic status on knowledge, attitude and practice of mother and her child regarding acute diarrheal diseases. Int $\mathrm{J}$ Community Med Public Health. 2017; 4(12): 4472-6

14. Dhingra D, Dabas A, Anand T, Pinnamaneni R. Maternal Knowledge, Attitude

Annexure 1: Reserach Tool

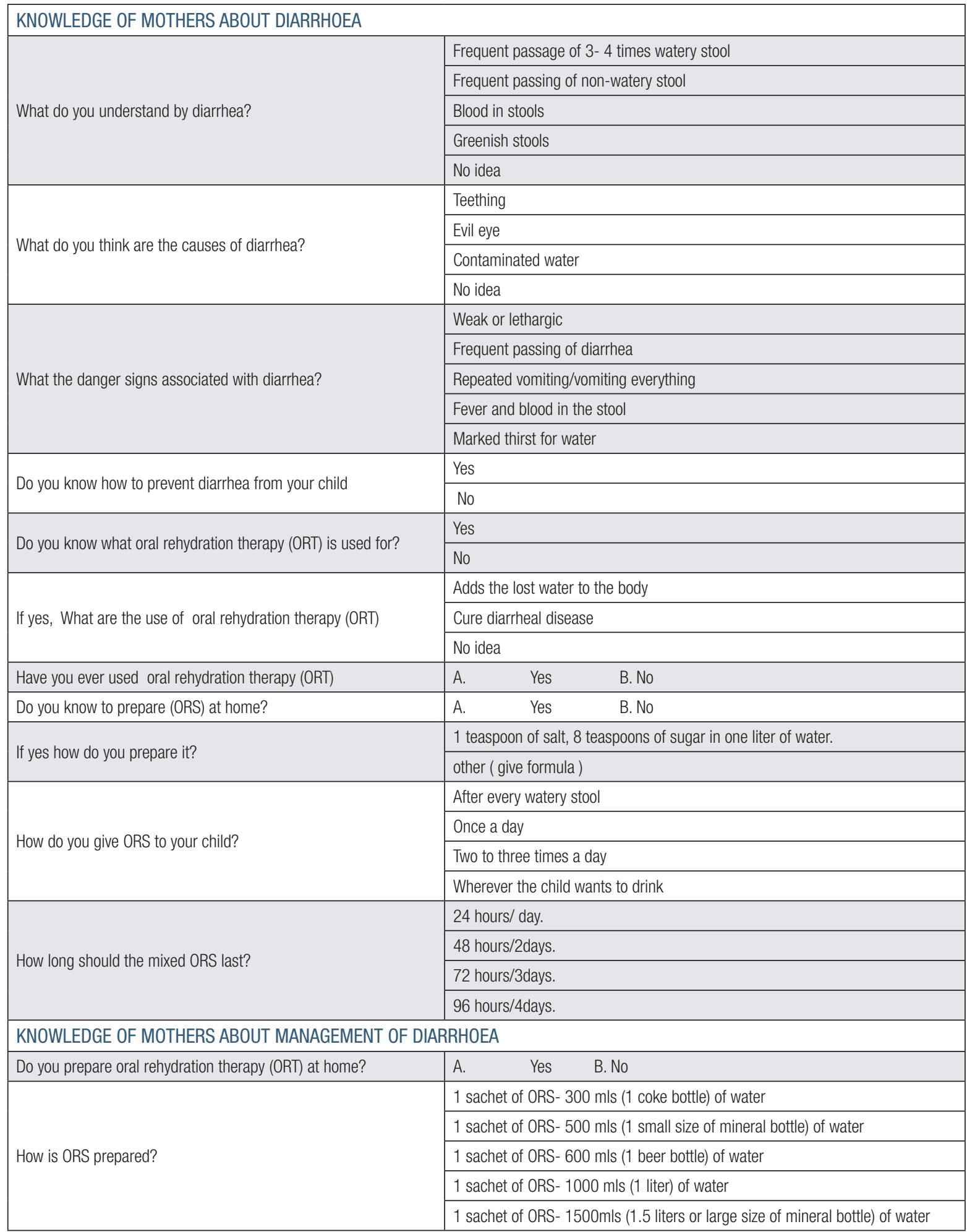




\begin{tabular}{|c|c|}
\hline \multirow{5}{*}{ Where did you seek help for your Diarrheal child? } & Hakeem \\
\hline & Faith Healers \\
\hline & Private drug-shop \\
\hline & Health center \\
\hline & Hospital \\
\hline \multirow{4}{*}{$\begin{array}{l}\text { When the child had diarrhea, did you breastfeed him/her less than } \\
\text { usual, about the same amount, or more than usual? }\end{array}$} & LESS \\
\hline & SAME \\
\hline & MORE \\
\hline & CHILD NOT BREASTFED \\
\hline \multirow{4}{*}{$\begin{array}{l}\text { When the child had diarrhea, was he/she offered less than usual } \\
\text { to drink and eat, about the same amount, or more than usual to } \\
\text { drink and eat? }\end{array}$} & LESS \\
\hline & SAME \\
\hline & MORE \\
\hline & NOTHING \\
\hline \multirow{3}{*}{ Where did you first go for advice or treatment? } & HOSPITAL \\
\hline & HEALTH CENTER \\
\hline & CLINIC \\
\hline \multirow{2}{*}{ Does your household have a special place for hand washing? } & Yes \\
\hline & No \\
\hline \multirow{5}{*}{ When do you usually wash your hands with soap? } & NEVER \\
\hline & Before preparing food \\
\hline & BEFORE FEEDING CHILDREN \\
\hline & AFTER DEFECATION \\
\hline & AFTER ATTENDING A CHILD WHO HAS DEFECATED \\
\hline
\end{tabular}

\section{Author's Contribution}

MH conceived the idea, planned the study, critically revised and supervised the study. FRM drafted the manuscript with data entry, analysis, interpretation and generation of tables and figures. SA, SMAS, SS and ZS collected the data and helped in statistical analysis. Authors agree to be accountable for all aspects of the work in ensuring that questions related to the accuracy or integrity of any part of the work are appropriately investigated and resolved.

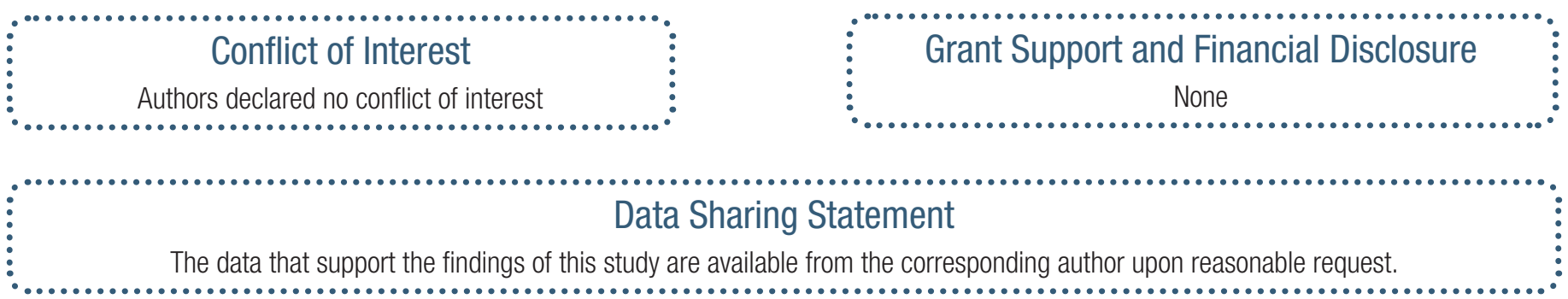

